\title{
USPOSABLJANJE ZA PSIHOLOŠKO POMOČ V SISTEMU VARSTVA PRED NARAVNIMI IN DRUGIMI NESREČAMI
}

\section{POVZETEK}

Naravne in druge nesreče vplivajo na žrtve nesreč, njihove družine, prijatelje, opazovalce in tudi na reševalce. Pri reševanju tudi reševalci doživijo stres, ki pa ga je mogoče olajšati z različnimi postopki. V sistemu varstva pred naravnimi in drugimi nesrečami so ti postopki opredeljeni v Smernicah za psihološko pomoč reševalcem, ki so predstavljene $v$ članku. Na podlagi smernic se po nesreči rě̌evalcu (na primer poklicneтu gasilcu) ponudi psihološka opora znotraj njegovega delovnega okolja s strani zaupnika, reševalca, usposobljenega za dajanje opore; pri hujših primerih pa dobi psihološko pomoč od psihologa zunaj svoje organizacije. V članku je predstavljeno usposabljanje za zagotavljanje psihološke pomoči reševalcem, ki se izvaja v Izobraževalnem centru za zaščito in reševanje $R S$.

Ključne besede: psihološka pomoč, usposabljanje zaupnikov, nesreče

\section{EDUCATING FOR PSYCHOLOGICAL SUPPORT IN THE SYSTEM OF PRO- TECTION AGAINST NATURAL AND OTHER DISASTERS - ABSTRACT}

Rescue personnel are faced with stress during and after incidents. In coping with stress, knowledge of stress management, protective behaviour, and social support can be of great help. Since incidents may also involve serious consequences, rescue personnel (for example professional fire fighters) are offered psychological and social support in the form of peer and external professional support, short defusing interviews after the critical incident at the end of the shift, comprehensive psychological trauma integration, and psychotherapy. The article presents information on the implementation of psychological support for rescue workers in the Education Centre for Civil Protection and Disaster Relief.

Keywords: psychological support, education for peer support, disasters

Dr. Andreja Lavrič, Uprava RS za zaščito in reševanje, Izobraževalni center za zaščito in reševanje Ig, andreja.lavric@guest.arnes.si 


\section{UVOD}

Potreba po psihološki pomoči pri izpostavljenosti kritičnim oziroma travmatičnim dogodkom je še posebno očitna pri nekaterih poklicih, pri katerih je pogostost takšnih izkušenj precej velika, na primer gasilcih, različnih reševalcih (potapljačih, jamarjih, kinologih, gorskih reševalcih), strokovnjakih za neeksplodirana ubojna sredstva, policistih in drugih. Stres pri navedenih poklicih so preučevale tako slovenske kot mednarodne raziskave. Metaraziskava, v katero so ameriški raziskovalci vključili 192 študij velikih nesreč z vsega sveta v zadnjih 40 letih, je preučila, kako naravne in druge nesreče vplivajo na duševno in fizično zdravje (Galea, Nandi in Vlahov, 2005). Ugotovili so, da so travmatične izkušnje razmeroma pogoste, saj jih v svojem življenju doživi več kot dve tretjini ljudi. Nesreče na ljudi vplivajo različno, vendar ugotavljajo, da se kot najpogostejša psihološka motnja pojavlja potravmatska stresna motnja.

$\mathrm{V}$ omenjeni raziskavi ugotavljajo, da se je prisotnost potravmatske stresne motnje pokazala pri 30 do 40 odstotkih žrtev nesreč. Pri reševalcih se je pokazala pri približno 10 do 20 odstotkih in pri prebivalcih nasploh pri približno petih do 10 odstotkih (Galea idr., 2005). Raziskava je tudi razkrila, da je prisotnost potravmatske stresne motnje pogostejša po nesrečah večjega obsega, ki jih povzroči človek, oziroma pri tehnoloških nesrečah kot pa pri naravnih nesrečah.

$\mathrm{V}$ raziskavah med slovenskimi reševalci in še posebej med poklicnimi gasilci (Svetina, 2007; Novak, 2008; Terdič, 2008) so ugotovili, da so za slovenske poklicne gasilce bolj stresni dogodki, ko so med intervencijo pri nesreči sami huje poškodovani, kjer je smrtno ali huje poškodovan sodelavec in če so bili poškodovani ali mrtvi bližnje osebe zaposlenega, ali če so bili poškodovani ali umrli otroci.

Da se po stresnih reševalnih akcijah gasilcem in drugim reševalcem daje psihološka pomoč, če jo ti potrebujejo, priporočajo številne mednarodne raziskave in smernice (EUTOPA, 2008; Joint Medical Committee NATO, 2008; Burger, 2012; TENTS, 2009). Ta priporočila so bila vključena tudi v slovenske Smernice za psihološko pomoč reševalcem (Lavrič, 2012), ki jih je izdala Uprava RS za zaščito in reševanje za razbremenitev reševalcev po hujših nesrečah.

\section{SMERNICE ZA PSIHOLOŠKO POMOČ REŠEVALCEM}

Smernice za psihološko pomoč v sistemu varstva pred naravnimi in drugimi nesrečami so predvsem namenjene psihološki podpori operaterjem v centrih za obveščanje, poklicnim gasilcem in prostovoljnim reševalcem znotraj sistema varstva pred naravnimi in drugimi nesrečami. Njihova uvedba omogoča preventivo pred poklicnim izgorevanjem, zmanjševanje stresnega odziva ter seznanitev z morebitnimi čustvenimi, miselnimi, telesnimi in vedenjskimi odzivi na krizne dogodke, hitrejše okrevanje po kritičnih dogodkih, graditev zaupanja in sodelovanja v skupini ter izmenjavo izkušenj.

Začetki uvajanja modela psihosocialne podpore za reševalce segajo v leto 2008, ko je Uprava RS za zaščito in reševanje začela raziskavo o modelu preventive pred stresom in 
o sistemu psihološke pomoči na področju varstva pred naravnimi in drugimi nesrečami, ki jo je opravil Oddelek za psihologijo Filozofske fakultete Univerze v Ljubljani (Svetina, 2007). Temu so sledile še druge raziskave, ki so predvsem preučevale stres pri gasilcih in operaterjih v klicnih centrih na številki 112 (Novak, 2008; Terdič, 2008; Korade in Kokošar, 2011).

Poleg priporočil mednarodnih smernic so bile v pomoč pri vzpostavljanju modela psihološke pomoči tudi konkretne izkušnje iz tujine, posredovane predvsem od švedskih in hrvaških strokovnjakov. Švedski poklicni gasilci in predstavniki Švedske agencije za zaščito in pripravljenost so s svojim programom o obvladovanju stresa ob kritičnih dogodkih (ang. Critical Incident Stress Management) vplivali na vzpostavitev slovenskega modela (Haasling, 2008).

O travmatskem stresu in socialnem kontekstu okrevanja po travmi so nam svoje znanje in izkušnje posredovali tudi strokovnjaki z zagrebške filozofske fakultete, ki so nas tudi povabili k evropskemu projektu European Network for Traumatic Stress (TENTS, 2009).

Pred uvedbo smernic psihološke pomoči za reševalce v sistem varstva pred naravnimi in drugimi nesrečami smo imeli tudi v Sloveniji dober vzgled tovariške podpore pri policistih. Projekt policijskih zaupnikov in 24-urne psihološke pomoči je uspešno stekel s psihologi, ki delajo s slovenskimi policisti (Policija, 2010). Z njihovo pomočjo in pomočjo psihologov Slovenske vojske smo tudi v sistemu zaščite in reševanja lahko uspešno pristopili k vzpostavljanju modela psihološke pomoči za reševalce.

Smernice predlagajo tri stopnje psihološke pomoči reševalcem po hujših nesrečah, ki se razmejujejo glede na to, kaj posameznik naredi zase, in za tem njegova bližnja okolica ter za tem pomoč strokovnjakov za nudenje psihološke pomoči.

Slika 1: Stopnje psihološke podpore in pomoči reševalcem

Pomoč znotraj organizacije

Pogovor z zaupniki

Notranja tehnična analiza

Razbremenilni pogovor po

intervenciji

Posameznik

Znanje o obvladanju stresa

Obvladanje tehnik sproščanja

Socialni odnosi

(Vir: Lavrič, 2013, str. 56)

Pomoč zunaj organizacije

Strnjena psihološka integraci-

ja travme

Psihološko svetovanje

Psihoterapija 
Prva stopnja oziroma stopnica na lestvi psihološke pomoči reševalcem je, da vsak reševalec sam pri sebi prevzame odgovornost za upravljanje stresa, pozna in uresničuje zaščitno vedenje ter krepi socialne odnose $\mathrm{z}$ družino, prijatelji in drugimi. Pomembno je sproščanje s telesno vadbo, različnimi interesnimi dejavnostmi in poznavanje tehnik sproščanja.

Pri obvladovanju stresa ima pomembno vlogo podpora socialnega okolja, predvsem najbližjih. Socialni odnosi vplivajo na spoprijemanje posameznika s stresom, pozitivna socialna podpora pripomore $\mathrm{k}$ občutkom uspeha in deluje preventivno na izgorevanje (Rakovec Felser, 2002). Visoka socialna podpora tako ublaži delovanje grozečih dogodkov. Payne in Walker (v Svetina, 2007) opredeljujeta različne oblike socialne opore, in sicer oporo v obliki koristnih informacij, otipljivo oporo v obliki konkretnih aktivnosti drugih, čustveno oporo, oporo v smislu potrditev posameznikovih prepričanj in občutkov ter socialno vključenost. Raziskave torej potrjujejo pomen medosebnih stikov za posameznikovo občutenje sprejetosti, ljubljenosti, potrjenosti in njihovo zaščitno vlogo med boleznijo in pred njenimi posledicami (Svetina, 2007).

Preventivno delovanje v obliki sproščanja omogoča učinkovito zmanjšanje delovanja simpatičnega živčnega sistema, organizem poživi in poveča sposobnost zbranosti ter spodbuja spomin in ustvarjalnost. Tako si posameznik obnovi energetske zaloge in se pripravi na soočanje s stresom (Svetina, 2007).

Obstajajo različne tehnike sproščanja, ki večinoma temeljijo na pravilnem in poglobljenem dihanju. Stres povzroči pomanjkljivo, nepravilno in plitvo dihanje, pri katerem ni trebušnega dihanja, uporablja se večinoma zgornji del pljuč, to pa ima za posledico pomanjkanje zadostne količine kisika v krvi, kar občutimo kot utrujenost, težo, težave z zbranostjo in nelagodje ter slabše razpoloženje. Zmanjša se tudi naša učinkovitost (Svetina, 2007).

$\mathrm{K}$ obvladovanju stresa in poznavanju zaščitnega vedenja veliko pripomorejo tudi usposabljanja s tega področja. Tako so reševalcem, ki delujejo $\mathrm{v}$ sistemu zaščite, reševanja in pomoči, namenja tovrstna usposabljanja v smislu preventive. Usposabljanja, ki jih izvaja Izobraževalni center za zaščito in reševanje RS, so številnim gasilcem, gorskim reševalcem, kinologom, jamarjem, potapljačem in drugim pomagala pri prepoznavanju stresa in soočanju z njim.

\section{USPOSABLJANIE ZAUPNIKOV V SISTEMU VARSTVA PRED NARAVNIMI IN DRUGIMI NESREČAMI}

Po zahtevnejših in bolj stresnih intervencijah lahko reševalci na podlagi smernic dobijo psihološko oporo od sodelavcev znotraj svojega delovnega tima, to je tako imenovanih zaupnikov.

Zaupniki so izkušeni zaposleni (na primer gasilci), ki v svojem delovnem okolju uživajo ugled in jim sodelavci zaupajo. Izbrani so s posebnim postopkom na podlagi svojih prijav ali pa so jih predlagale posamezne enote. Zaupniki morajo izpolnjevati naslednje pogoje: stari morajo biti najmanj 30 let, imeti morajo najmanj pet let operativnih izkušenj z 
intervencij, imeti morajo sposobnost empatije, usposobljeni morajo biti za opravljanje razbremenilnih pogovorov in praviloma naj ne bi bili vodje.

Kandidate za zaupnike pred usposabljanjem psihološko preizkusijo s pisnimi testi in na pogovoru, ki ga izvedejo psihologi. Po uspešno opravljenem testiranju se začne usposabljanje v Izobraževalnem centru za zaščito in reševanje RS na Igu. Po končanem usposabljanju morajo uspešno opraviti pisni in ustni izpit pred izpitno komisijo.

Po intervencijah, ko je na primer ogroženo življenje reševalca ali sodelavca, če je poškodovan član reševalne ekipe ali so morda v nesreči udeležene bližnje osebe reševalca ali poškodovani otroci, se opravi razbremenilni pogovor z zaupnikom. Na tej stopnji psihološke podpore si poskušajo reševalci pomagati v okvirih tovariške pomoči znotraj svoje organizacije.

Prvo usposabljanje zaupnikov, ki je bilo v Izobraževalnem centru za zaščito in reševanje RS končano leta 2012, je bilo izvedeno v sodelovanju s strokovnjaki iz Švedske agencije za zaščito in pripravljenost ter domačimi predavatelji. Usposabljanja za izvajanje psihološke podpore za zaupnike so se udeležili poklicni gasilci in operaterji v centrih za obveščanje. Po uvodnem delu v spletni učilnici na portalu izobraževalnega centra o ravnanju ob stresu je v nadaljevanju s predstavniki slovenske policije in vojske ter švedske reševalne agencije izvedeni večdnevni o soočanju s stresom, komunikaciji, postopkih razbremenjevanja in drugih vsebinah.

Usposabljanje je bilo izpeljano s podporo Skupnosti gasilsko reševalnih zavodov Slovenije, ki je prek vodij gasilskih enot podprla izvajanje psihološke pomoči v svojih enotah. Na podlagi tega je večina poklicnih gasilskih enot pridobila usposobljene zaupnike za izvajanje razbremenilnih pogovorov s svojimi sodelavci. V sistemu varstva pred naravnimi in drugimi nesrečami je tako začelo delovati 39 zaupnikov poklicnih gasilcev in šest zaupnikov operaterjev v centrih za obveščanje, ki so tako usposobljeni za zagotavljanje psihološke opore sodelavcem.

\section{PSIHOLOŠKA POMOČ PO HUJŠIH NESREČAH}

Potravmatski stres se lahko pojavi pri reševalcih, ki so preživeli dogodek, ki ni običajna človekova izkušnja, in podoživljajo ta dogodek s simptomi povečanega vzburjenja. V nasprotju s stresnimi dogodki doživljanje travmatičnega dogodka ni odvisno od kognitivne ocene posameznika, temveč so travmatični dogodki po svoji naravi takšni, da močno prizadenejo vse ljudi in jih vržejo iz ravnotežja. Takšni dogodki so nenadni in izzovejo intenziven strah, občutek groze ter nemoči. Posamezniki so lahko v dogodkih neposredno udeleženi oziroma prizadeti, lahko nastopajo kot neposredni opazovalci tragedije ali so tesno osebno povezani z osebo, ki je travmatični dogodek doživela (Arambašić, 2000).

Določeni odzivi posameznika (Arambašić, 2000) na travmatični dogodek so razumljivi, pričakovani in za nenormalne okoliščine povsem normalni. Trajajo lahko nekaj tednov ali celo mesecev in se lahko pojavijo takoj po dogodku ali celo čez nekaj mesecev. Če po 
intenzivnosti, obsegu, trajanju in stopnji, do katere jih posameznik še lahko prenaša, presežejo določeno mero, govorimo o potravmatskem stresnem sindromu. V tem primeru je potrebna tudi psihoterapevtska pomoč. Potravmatski stresni sindrom je torej dolgotrajna posledica travmatičnega doživetja.

Stopnja posameznikove psihične in psihosocialne prizadetosti je odvisna od več dejavnikov. Mikuš Kos in Slodnjak (2000) navajata, da je odvisna od narave in intenzivnosti travme, stopnje izpostavljenosti, osebnih lastnosti posameznika, značilnosti življenjskega okolja in pomoči, ki so jo zagotovili posamezniku. Posamezniki, ki bolje prenašajo učinkovanje stresorjev in se manj odzivajo na stres, tudi bolje obvladujejo travmatska doživetja.

V primerih intervencij s hujšimi posledicami, ko je reševalec priča smrti ali hujši poškodbi sodelavca, sam doživi hujšo poškodbo ali so v nesreči umrli otroci, morda celo bližnje osebe reševalca, mu mora biti zagotovljena psihološka pomoč. Ta poteka v obliki razbremenilnega večdelnega pogovora, imenovanega strnjena psihološka integracija travme, in naknadnega svetovanja, ki ju izvajajo psihologi Službe za psihološko pomoč, ki pogodbeno sodelujejo z Upravo RS za zaščito in reševanje.

Zadnji izmed korakov psihološke pomoči reševalcem je psihoterapija, ki je namenjena reševalcem z akutnimi ali kroničnimi potravmatskimi stresnimi motnjami. Raziskave navajajo več uspešnih psihoterapij, še posebej pa omenjajo kognitivno vedenjsko terapijo, usmerjeno na travmo, in desenzitizacijo ter ponovno predelavo z očesnim gibanjem (TENTS, 2009).

Kognitivna vedenjska terapija (ang. Cognitive Behavioural Therapy - CBT) je usmerjena na kognitivno in vedenjsko izogibanje pri potravmatskih stresnih motnjah. Poleg usmerjenosti na travmatični dogodek vključuje tudi obvladovanje anksioznosti, psihološko izobraževanje in metode kognitivnega preoblikovanja (TENTS, 2009). Klinično pomembno vpliva na vse stopnje potravmatskega stresnega sindroma. Priporoča se kot primarna terapija za žrtve nesreč z akutnimi ali kroničnimi potravmatskimi stresnimi motnjami (TENTS, 2009).

Druga možna terapija je desenzitizacija in ponovna predelava z očesnim gibanjem (ang. Eye Movement Desensitization and Reprocessing - EMDR). Terapija vključuje spremembo disfunkcionalno shranjenih izkušenj v prilagodljivo zamenjavo, ki izboljšuje duševno zdravje. Prispeva k zmožnostim spopadanja s stisko zaradi travmatičnega spomina ter zmanjša moč motečih misli in čustev (TENTS, 2009).

Psihoterapevtsko pomoč morajo reševalci poiskati zunaj sistema varstva pred naravnimi in drugimi nesrečami. 


\section{SKLEP}

Reševalci, ki rešujejo v sistemu varstva pred naravnimi in drugimi nesrečami, se po travmatičnih dogodkih soočajo s tragičnimi posledicami. Po teh »nenormalnih« dogodkih, kot je na primer smrt otrok, je popolnoma »normalno«, da imajo močne fizične in čustvene odzive. V zadnjih nekaj letih se uveljavljajo prizadevanja, da reševalci po kriznem dogodku spregovorijo o teh odzivih s svojimi sodelavci v poznanem in varnem okolju.

Zaupniki, to so gasilci in operaterji v klicnih centrih 112, imajo podlago za dajanje psihološke podpore svojim sodelavcem v Smernicah za psihološko pomoč v sistemu varstva pred naravnimi in drugimi nesrečami. Smernice predlagajo tri stopnje psihološke pomoči reševalcem po hujših nesrečah, ki se stopnjujejo glede na to, kaj posameznik sprva lahko sam naredi zase, kako mu po kriznem dogodku lahko pomagajo sodelavci v njegovi delovni enoti ter za tem kakšno psihološko pomoč mu lahko dajejo strokovnjaki, na primer psihologi ali psihoterapevti.

Zaupniki se za dajanje psihološke podpore usposabljajo v Izobraževalnem centru za zaščito in reševanje RS, prav tako tudi psihologi, ki delujejo v sistemu varstva pred naravnimi in drugimi nesrečami.

\section{LITERATURA}

Ajduković, D. (2011). TENTS-TP Radionica treninga trenera o psihotraumi. Zagreb: Filozofska fakulteta, Sveučilište u Zagrebu.

Arambašić, L. (ur.). (2000). Psihološke krizne intervencije: psihološka prva pomoć nakon kriznih događaja. Zagreb: Društvo za psihološku pomoć.

Bisson, J. in Andrew, M. (2007). Psychological treatment of post-traumatic stress disorder (PTSD). Cochrane Database of Systematic Reviews, 3, 1-118. Pridobljeno s http://onlinelibrary.wiley.com/ doi/10.1002/14651858.CD003388.pub3/pdf

Burger, N. (2012). Guidelines psychosocial support for uniformed workers. Diemen: Impact.

Dass Brailsford, P. (2007). A Practical Approach to Trauma. Los Angeles: Saga Publications.

Report to the general assembly. (2007). Praga: European Federation of Professional Psychologists Associations.

Psychosocial interventions A handbook. (2009). Copenhagen: International Federation Reference Centre for Psychosocial Support.

European Network for Traumatic Stress (TENTS). (2009). TENTS Guidelines. Amsterdam: Academic Medical Center, University of Amsterdam.

EUTOPA. (2008). Multidisciplinary guideline Early psychosocial interventions after disasters, terrorism and other shocking events. Amsterdam: Trimbos Institute on behalf of the National Steering Committee on Multidisciplinary Guideline Development in Mental Health Care.

Galea, S., Nandi, A. in Vlahov, D. (2005). The Epidemiology of Post-Traumatic Stress Disorder after Disasters. Epidemiologic Reviews, 27/2005, 78-91.

Hassling, P. (2008). Razbremenilni pogovori, gradivo za predavanja. Ljubljana: Uprava RS za zaščito in reševanje.

IASC Guidelines on Mental Health and Psychosocial Support in Emergency Settings. (2007). Geneva: IASC. 
Joint Medical Committee NATO. (2008). Psycho-social care for people affected by disaster and major incidents. Pridobljeno s http://www.healthplanning.co.uk/nato/NATO_Guidance_Psychosocial_Care_for_People_Affected_by_Disasters_and_Major_Incidents.pdf

Korade, D. in Kokošar, I. (2011). Psihološki vplivi nesreč na delavce v centrih za obveščanje in njihova pripravljenost na soočanje z njimi v delovnem procesu. Ljubljana: Fakulteta za socialno delo Univerze v Ljubljani.

Larson, G. in Österdahl, L. (1996). Crisis Support. Karlstad: Swedish Rescue Service Agency.

Lavrič, A. (2009). Psihosocialna oskrba po nesrečah. Ujma, 23, 217-222.

Lavrič, A. (2011). Psihosocialna podpora reševalcem. Ujma, 25, 297-303.

Lavrič, A. (2012). Smernice za psihosocialno pomoč reševalcem - sistem varstva pred naravnimi in drugimi nesrečami. Ljubljana: Uprava RS za zaščito in reševanje.

Lavrič, A. (2013). Psihološka pomoč reševalcem v sistemu varstva pred naravnimi in drugimi nesrečami. Revija 112, 1, 55-57.

Mikuš Kos, A. in Slodnjak, V. (2000). Nesreče, travmatski dogodki in šola. Ljubljana: DZS.

Post-traumatic stress disorder (PTSD) The management of PTSD in adults and children in primary and secondary care. (2005). London: National Institute for Health and Clinical Excellence.

Novak, M. (2008). Stres pri poklicnih gasilcih (Diplomsko delo). Filozofska fakulteta Univerze v Ljubljani, Ljubljana.

Policija. (2010). Policijski zaupniki. Pridobljeno s http://www.policija.si/images/stories/NovinarskoSredisce/SporocilaZaJavnost/2010/oktober/07-psiholoska_pomoc/policijski_zaupniki.pdf

Policija. (2010). 24-urna psihološka pomoč. Pridobljeno s http://www.policija.si/images/stories/NovinarskoSredisce/SporocilaZaJavnost/2010/oktober/07-psiholoska_pomoc/24-urna_psih_pomoc.pdf.

Rakovec Felser, Z. (2002). Zdravstvena psihologija. Maribor: Visoka zdravstvena šola.

Seynaeve, G. J. R. (2001). Psycho-Social Support in situations of mass emergency, European Policy Paper concerning different aspects of psycho-social support for people involved in major accidents and disasters. Brussels: Ministry of Public Health.

Svetina, M. (2007). Zaključno poročilo o rezultatih opravljenega raziskovalnega dela na projektu $v$ okviru ciljnega raziskovalnega programa (CRP) Znanje za varnost in mir 2006-2010. Ljubljana: Filozofska fakulteta Univerze v Ljubljani.

Terdič, P. (2008). Stres pri poklicnih gasilcih - Gasilska brigada Ljubljana (Diplomsko delo). Fakulteta za socialno delo Univerze v Ljubljani, Ljubljana.

Tušak, M. in Masten, R. (2008). Stres in zdravje. Ljubljana: Fakulteta za šport Univerze v Ljubljani. 